\title{
Antibacterial coating of Ti-6Al-4V surfaces using silver nano-Powder Mixed Electrical Discharge Machining
}

\author{
Viet D. Bui ${ }^{\mathrm{a}, *}$, James W. Mwangi ${ }^{\mathrm{a}}$, Ann-Kathrin Meinshausen ${ }^{\mathrm{b}}$, Andreas J. Mueller ${ }^{\mathrm{c}, \mathrm{d}}$, Jessica Bertrand ${ }^{\mathrm{b}}$, \\ Andreas Schubert ${ }^{\mathrm{a}, \mathrm{e}}$ \\ ${ }^{a}$ Chemnitz University of Technology, Professorship of Micromanufacturing Technology, Reichenhainer Strasse 70, 09107 \\ Chemnitz, Germany \\ ${ }^{b}$ Otto von Guericke University Magdeburg, Department of Orthopaedic Surgery, Leipziger Strasse 44, 39120 Magdeburg, \\ Germany \\ ${ }^{c}$ Otto von Guericke University Magdeburg, Institute of Molecular and Clinical Immunology, Leipziger Strasse 44, 39120 \\ Magdeburg, Germany \\ ${ }^{d}$ Helmholtz Centre for Infection Research, Inhoffenstrasse 7, 38124 Braunschweig, Germany \\ ${ }^{e}$ Fraunhofer Institute for Machine Tools and Forming Technology, Reichenhainer Strasse 88, 09126 Chemnitz, Germany
}

\begin{abstract}
Previous studies have revealed the potential of powder mixed electrical discharge machining (PMEDM) with regards to concurrently machining part geometry and coating an antibacterial layer on medical devices. This study is aimed at further demonstrating this potential. In order to do so, the PMEDM process was varied by adding different concentrations of silver nano-particles into the dielectric fluid and used to machine Ti-6Al-4V. Afterwards, the resulting machined and coated surfaces were characterized with regards to surface integrity, the coating layer's thickness, microhardness and chemical elements as well as antibacterial property. Material removal rate, tool wear and pulse signals were also analysed in order to give an insight on process feasibility. From both qualitative and quantitative results, it could be established that the surfaces machined and coated by PMEDM method have demonstrated a significant reduction of not only the amount of $S$. aureus bacteria, but also the number of bacterial clusters on the coating layer's surface. Moreover, the coating layer's silver content, which depends on the powder concentration suspended in the dielectric fluid, plays a vital role in the antibacterial property. As compared to surfaces without silver, surfaces containing approximately $3.78 \%$ silver content showed a significant decrease in both bacterial numbers and clusters, whereas a further increase in silver content did not result in a considerable bacterial number and cluster reduction. Regarding the machining performance, as compared to EDM without powder, machining time is remarkably decreased by using the PMEDM method.
\end{abstract}

Keywords: Antibacterial coating; PMEDM; titanium implants; coating layer; antibacterial property.

\footnotetext{
* Corresponding author

Email address: viet.bui-duc@s2016.tu-chemnitz.de (Viet D. Bui)
} 


\section{Introduction}

2

The demand for medical implants has been rapidly increasing. For example, it is predicted that the medical device market will record a minimum compound annual growth rate of $4.5 \%$ between 2017 and $2024[1,2]$. However, implant related infections still pose a major challenge for the medical device industry. Although antibiotics have been successfully used in clinical treatments [3], antibacterial coatings of metal implants are considered as potential long term solutions to this problem [4].

\subsection{Antibacterial coating processes}

In order to coat an antibacterial layer on metal surfaces, several methods have been studied and their efficiency demonstrated. For example, titanium oxide layers deposited on titanium substrates by anodic oxidation showed a significant reduction in the number of viable $E$. coli on the coating surface [5]. These layers were combined with silver using plasma electrolytic oxidation [6], anodic spark deposition [7] or plasma spraying [8], in order to enhance the antibacterial properties. In other studies, coating layers with a thickness of approximately $2 \mu \mathrm{m}$ were deposited on titanium surfaces by physical vapor deposition (PVD), with a significant antibacterial potency and the absence of cytotoxic effects being reported [9]. Moreover, chemical vapour deposition (CVD) has been used for silver-silica surface coatings and has shown a significant reduction of a variety of bacteria [10]. Furthermore, PVD and CVD methods have also been studied appertaining to coating thin films for medical application $[11,12]$. On the other hand, thermal spraying has been used in coating silver-containing hydroxyapatite layers on titanium implant surfaces. The results of both in vitro and in vivo studies showed a significant reduction in the number of $S$. aureus bacteria on these layers as compared to hydroxyapatite layers $[13,14]$. Another method, namely ion implantation, has been studied and has shown excellent antibacterial effects [15] and no cytotoxicity of the coating surface [16]. Other results have shown that silver ion implantation is more suitable than copper ion implantation for coating antibacterial surfaces of medically applied metals [17].

\subsection{PMEDM for surface modification}

PMEDM has been studied for surface modification whereby emphasis has been on characterizing how the process mechanism allows for material deposition in and onto the machined surface [18]. During the machining process, materials from particles that are mixed into the dielectric fluid are transferred to the workpiece surface, therefore modifying its characteristics. Research has shown that the microhardness of $\beta$ titanium implant surfaces has been increased 2-fold when silicon particles are suspended in the dielectric fluid [19]. The PMEDM process also enhances fatigue endurance and biocompatibility of $\beta$-titanium implants for orthopedic applications [20]. An approximate $76 \%$ surface hardness increase as well as an elimination of microcracks on the machined surface have been reported after adding titanium powder into hydrocarbonbased dielectric fluid [21]. In another study, silicon and manganese powders were used to improve recast layer 
hardness by approximately $40 \%$ as compared to EDM process without powder [22]. Both microhardness and wear resistance were significantly increased by mixing tungsten powder into the dielectric fluid [23]. PMEDM using titanium carbide particles has also been combined with ultrasonic vibration to not only improve machining performance, but also to enhance the hardness and wear resistance of the workpiece surface [24].

Similar to conventional EDM, the modified layer while using PMEDM is also affected by machining parameters such as current and pulse-on-time. Besides, powder concentration is an important parameter which influences the properties of the resulting machined surface [25]. Powder material has shown its impact during PMEDM. For example, using $\mathrm{Al}_{2} \mathrm{O}_{3}$ powder provided a higher modified layer thickness whereas TiC powder resulted in a higher machined surface hardness [26]. The thickness of the modified layer has also been increased by using smaller powder particle sizes [27]. However, the modified layer thickness was not affected by varying machining time [28].

\subsection{Summary of literature review}

From literature, it can be established that many methods have been used for coating antibacterial layers on medical materials. However, these methods, until now, are only used for coating. PMEDM has demonstrated its ability in, not only machining medical materials, but also in modifying their surfaces. Therefore, a method that has the ability to concurrently machine and coat an antibacterial layer on medical device surfaces is proposed and investigated in this study. Moreover, so as to clearly understand how the process influences the coating layer, the PMEDM machining and coating mechanism is explained.

\section{PMEDM's machining and coating mechanism}

The PMEDM machining and coating mechanism is, as shown in Fig. 1, best explained by categorizing it into four discharge phases as follows:

(i) Preparation phase: After applying a potential difference between the tool and workpiece electrodes, powder particles in the electric field arrange themselves in chains (Fig. 1(a)) [29].

(ii) Ignition phase: Where voltage is highest and exceeds the dielectric resistivity, a single ignition occurs after which multiple ignitions take place (Fig. 1(b)) [30].

(iii) Discharge phase: A plasma channel, composed of ion and electron flows which collide and implant into the workpiece and tool electrode surfaces respectively, is formed (Fig. 1(c)). Thermal energy causes the melting of materials from workpiece, tool electrode as well as powder particles. The plasma channel grows until reaching a balance point between the internal pressure of the formed bubble and the dielectric fluid's hydrostatic pressure (Fig. 1(d)). Thereafter, it bursts (Fig. 1(e)) and blows off most of the molten mixture of materials from the tool electrode, powder particles and workpiece. 


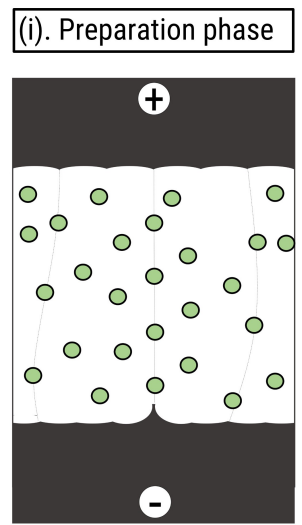

(a)
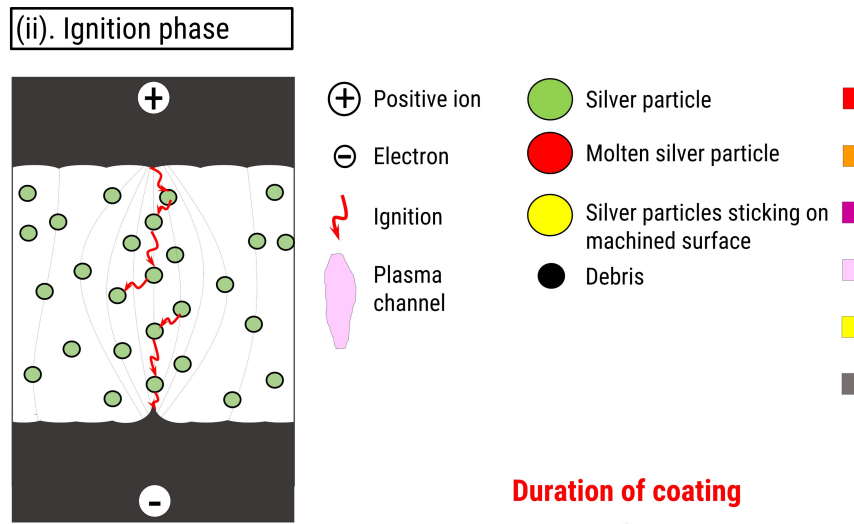

Molten material

Heat affected layer during machining

Recast layer at a high temperature

High temperature material

Coating layer after PMEDM

Heat affected layer after machining

Duration of coating

(iii). Discharge phase

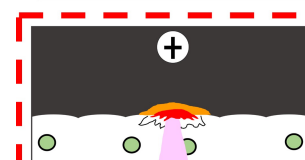

$\mid \begin{array}{lllll}0 & 0 & 0 & 0 & 0 \\ 0 & 0 & e_{5} & 0 & 0\end{array}$

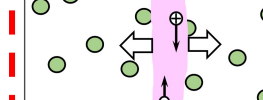

$10_{0}^{0} 0^{1} 0$
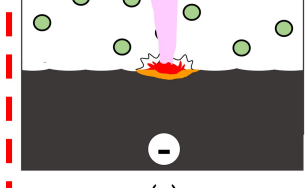

(c) (b)

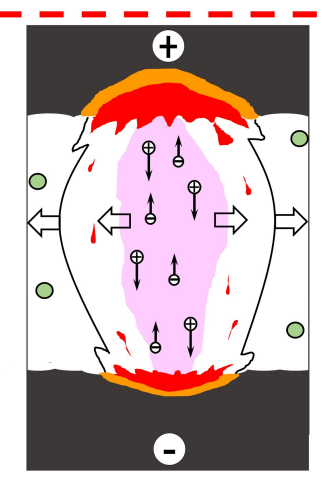

(d)

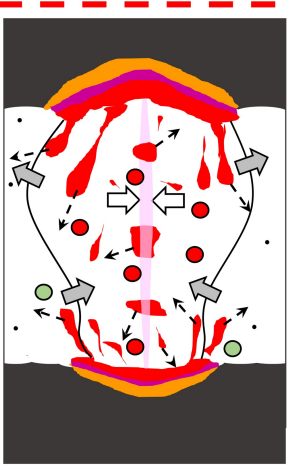

(e)

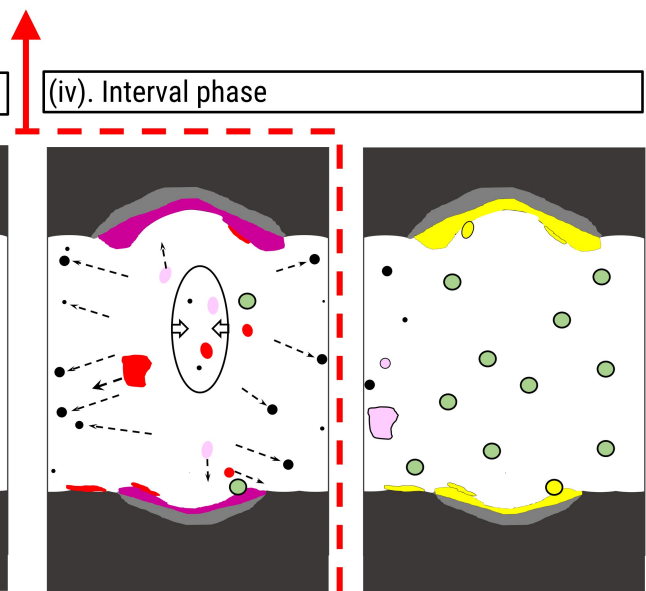

(g)

Figure 1: PMEDM's machining and coating mechanism of a single spark. Stages (c-f) represent the duration of the concurrent machining and coating process.

However, some of the molten material remains on the workpiece surface thus generating the main part of the coating layer.

(iv) Interval phase: During this phase, the dielectric fluid cools the workpiece and removes the machined debris. Nevertheless, some of the molten materials, after bursting, are sputtered and re-solidified onto the machined surface. In addition, some particles, which remain partially or fully molten during the recast layer's formation process, stick to sections of the machined surface and forms the rest of the resulting coating layer (Fig. 1(f)). Afterwards, fresh dielectric fluid, containing new powder particles, continues flowing and cooling the workpiece in anticipation of a new discharge cycle (Fig. 1(g)). 


\section{Methodology}

\subsection{Material selection}

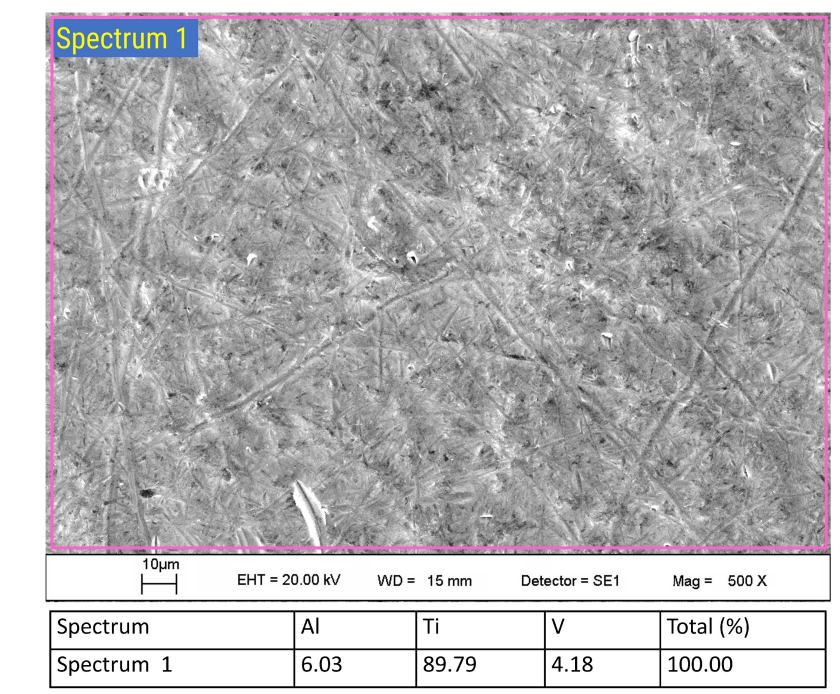

Figure 2: Chemical composition of the sample before machining and coating.

Ti-6Al-4V is one of the key materials used to manufacture medical devices owing to its desirable properties which include excellent biocompatibility, corrosion resistance and high fatigue strength among others. In this study, $(30 \times 20 \times 1) \mathrm{mm}^{3} \mathrm{Ti}-6 \mathrm{Al}-4 \mathrm{~V}$ sheets were used as workpieces. To analyse the chemical composition of the samples before machining, Energy dispersive X-Ray spectroscopy (EDS) was used. The results were as presented in Fig. 2.

From literature, it is clear that silver has a stronger antibacterial effect and is more biocompatible than other materials such as copper, zinc or titanium dioxide. In addition, various coating methods have shown no cytotoxicity when depositing silver on medical device surfaces. For these reasons, silver nano-particles (99.9\% purity) with diameters of $\approx 50-60 \mathrm{~nm}$ were utilised. The choice of particle size is significant since it not only influences the coating layer, but is also significant to the stability of the PMEDM process because large particles could clog the narrow machining gap that is necessary for the sparking process.

\subsection{Sample preparation}

In this study, the antibacterial property of the coating layer, which is dependent on silver content deposited in the coating surface during the PMEDM process, is evaluated. In order to do so, the surface roughness and structure of the samples have to be relatively similar, since they influence bacterial adhesion and growth. Moreover, surfaces with $\mathrm{R}_{a}>0.2 \mu \mathrm{m}$ not only increase plaque accumulation [31], but also facilitate biofilm formation [32]. Therefore, this $\mathrm{R}_{a}$ value was referenced for designing surface roughness of the investigated samples. 
For the antibacterial evaluation, 11 points were concurrently machined and coated on the workpiece surface as shown in Fig. 3. The point numbered "0" was machined without silver powder whereas points "1" to "10" were machined with varying silver powder concentrations suspended in the dielectric fluid from low to high respectively.

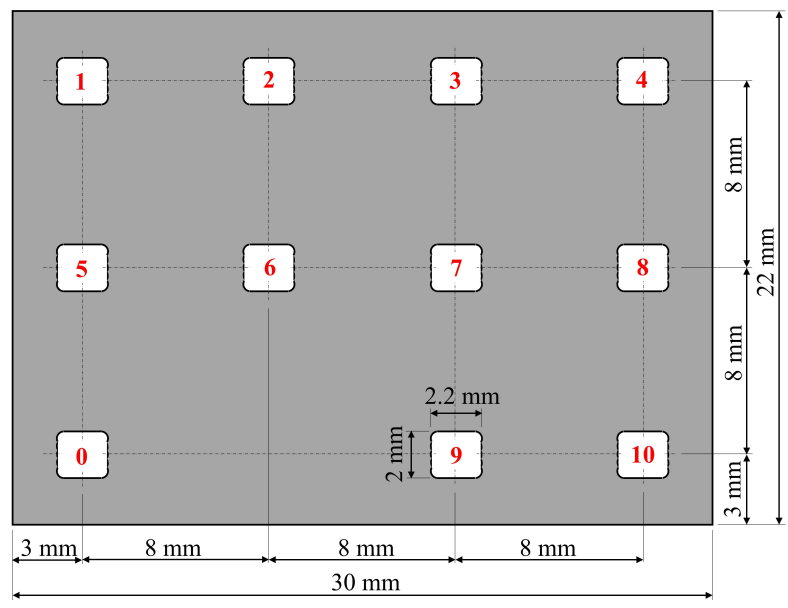

Figure 3: Arrangement of the machined points (white color) on the workpiece.

\subsection{Experimental setup}

The results from preliminary researches $[33,34]$ showed that silver powder concentration plays a vital role in the deposited silver content. However, it only caused a negligible change on surface roughness. Furthermore, other factors such as discharge energy, dielectric material and electrode size have significant influences on both roughness and chemical composition of the machined surface. Based on these findings, experimental conditions for this study were established as can be seen in Table 1.

Table 1: Experimental conditions.

\begin{tabular}{ll}
\hline Machine & Sarix $100 \mu$-EDM machine \\
\hline Tool electrode & - Material: WC-6 wt. $\%$ Co \\
& - Outer diameter: $0.6 \mathrm{~mm}$ \\
& - Inner diameter: $0.17 \mathrm{~mm}$ \\
\hline Dielectric fluid & HEDMA111 hydrocarbon \\
\hline Powder concentrations & $0 ; 2.5 ; 5 ; 7.5 ; 10 ; 12.5 ; 15 ; 17.5 ; 20 ; 22.5$ and $25(\mathrm{~g} / \mathrm{l})$ \\
\hline Discharge energy & $\approx 9.98(\mu \mathrm{J})$ \\
\hline Polarity & Positive at tool electrode \\
\hline
\end{tabular}

In addition, since discharge energy plays an essential role in not only the surface roughness, but also the 
thickness of the resulting coating layer, it is necessary to establish the discharge energy boundary which is suitable for realising the aforementioned $\mathrm{R}_{a}=0.2 \mu \mathrm{m}$ in PMEDM. It enables a discharge energy increment which results in a thicker coating layer and consequently allows for a better analysis. For this reason, extra experiments were carried out using various discharge energies $(\approx 9.98 \mu \mathrm{J}, \approx 17.5 \mu \mathrm{J}$ and $\approx 24.46 \mu \mathrm{J}) \mathrm{using}$ a $25 \mathrm{~g} / 1$ powder concentration in the dielectric fluid.

In order to carry out the experiments, due to a high-density powder settling at the bottom of the tank, a suitable circulation system as shown in Fig. 4 was angularly designed for tank 1. It ensures that all dielectric fluid flows out of this tank and into tank 2 where a stirrer is used to continuously mix silver particles with the dielectric fluid.

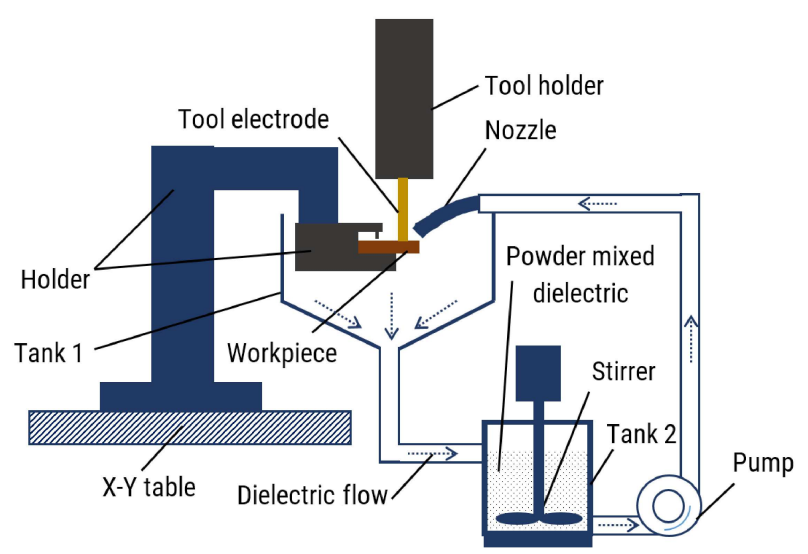

Figure 4: Schematic showing the designed PMEDM dielectric fluid circulation system.

As regards the geometry of the machined and coated surface, an area was machined and coated as shown in Fig. 5. Five overlapping machining paths of the tool electrode's trajectory (shown in blue color) with a $20 \mu \mathrm{m}$ cutting depth are repeated three times to achieve a $60 \mu \mathrm{m}$ target depth.

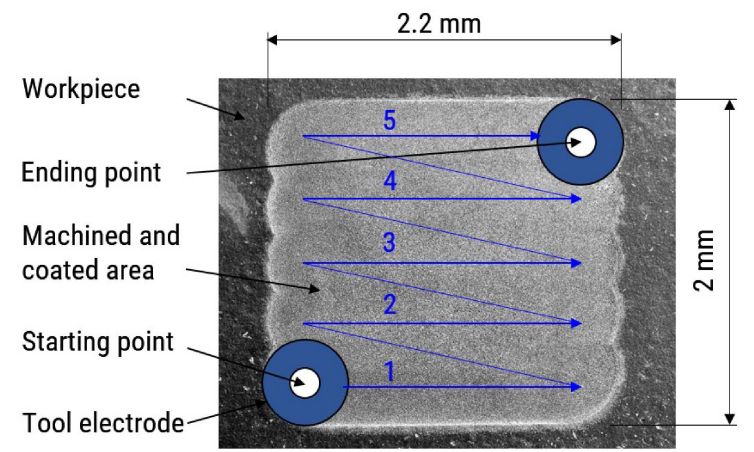

Figure 5: Schematic showing the machined and coated area and tool electrode's trajectory. 


\subsection{Coating characterization}

For effective analysis of the coating layer, the samples have to be carefully analysed. To do so, after machining, the samples were cleaned for 10 minutes in an ultrasonic bath filled with ethanol at room temperature, and then dried. Afterwards, their surface topography and composition was analysed using a scanning electron microscope (SEM) and energy dispersive X-Ray spectroscopy. A Keyence VK9700 3D Laser scanning confocal-microscope was used to scan the machined surfaces after which MountainsMap 7.4 scanning topography software was used to analyse surface roughness, surface structure and the volume of removed material. For microhardness testing, the measurement according to "Quasi Continuous Stiffness Measurement" (DIN EN ISO 14577) was performed by an UNAT nanoindenter for not only the Ti-6Al-4V substrate, but also the coating surfaces containing different silver contents.

In order to analyse the coating layer's cross section, the samples were carefully grinded, polished by a wet abrasive paper and then chemically etched using a Kroll solution (1.5\% hydrofluoric acid and $4 \%$ nitric acid in water). Afterwards, SEM and EDS were used to observe and analyse the thickness as well as the elemental composition of the coating layer.

\subsection{Material removal rate and tool wear rate characterization}

Apart from demonstrating the PMEDM's performance on machining, it is also important to investigate the material removal rate (MRR) and tool wear rate (TWR). In order to do so, wear length, after specified machining duration, was measured by an in-process measuring program. Furthermore, the machining time of each experiment was recorded, thus allowing MRR or TWR to be calculated by a quotient of "material removal volume" or "tool wear volume" per machining time, respectively.

\subsection{Antibacterial tests}

As regards to the antibacterial property of the layer coated by PMEDM method, S. aureus SH1000 pSB2035 [35] constitutively expressing green fluorescent protein (GFP) was cultured overnight. The coated Ti-6Al-4V test plate was incubated with $25 \mathrm{ml}$ lysogeny broth (LB) and inoculated with a 1:1000 dilution of the $S$. aureus overnight culture with an optical density of 1 at t $600 \mathrm{~nm}\left(\mathrm{OD}_{600}\right)$. After 24 hours of incubation, the coated $\mathrm{Ti}-6 \mathrm{Al}-4 \mathrm{~V}$ test plate was removed, washed once with phosphate buffered saline and subsequently fixed with $4 \%$ paraformaldehyde for 30 minutes at room temperature. The amount of bacteria and clusters was analysed in $630 \mathrm{x}$ magnification microscopic pictures (Zeiss fluorescence microscope Axio Observer.Z1) of the respective areas on the coated Ti-6Al-4V test plate. GFP fluorescence was excited at $488 \mathrm{~nm}$ and read out at $500-550 \mathrm{~nm}$. Four areas on each numbered coating surface (from " 0 " to "10") were evaluated and the mean values are given with SEM. 


\section{Results and discussion}

To evaluate the PMEDM's efficiency in concurrent machining part geometry and coating an antibacterial surface, different analysis criteria such as discharge energy, the coating layer's antibacterial property and microhardness, the deposited silver distribution, as well as machining performance are analysed and discussed.

\subsection{Influence of discharge energy on surface roughness}

Regarding the influence of the pulse energy on surface roughness, as shown in Fig. 6, the roughness values of the samples are rapidly increased on increasing the discharge energy. It can also be realised that a $0.2 \mu \mathrm{m} \mathrm{R} \mathrm{R}_{a}$ value of the PMEDMed surface could be achieved as long as the discharge energy was $\leq 17.5 \mu \mathrm{J}$.

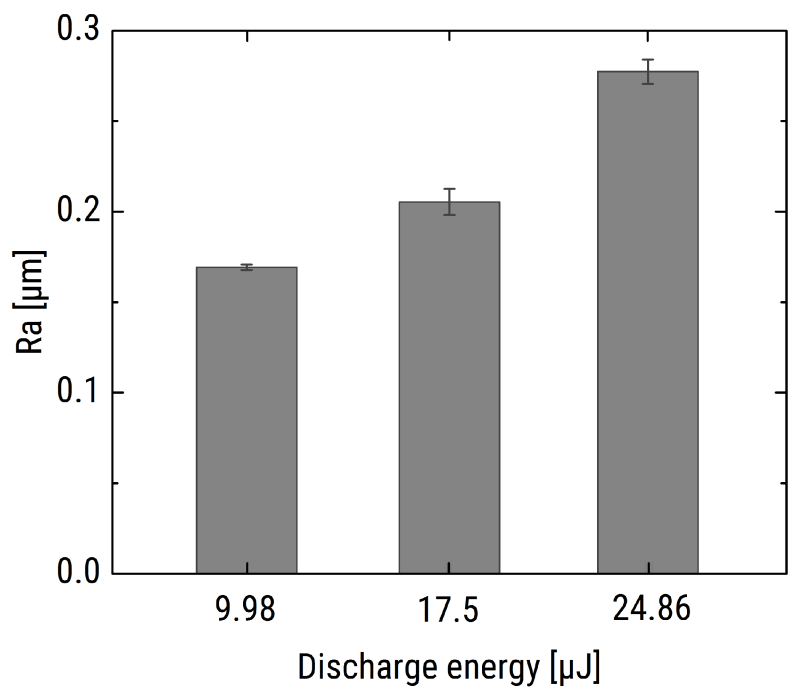

Figure 6: $\mathrm{R}_{a}$ surface roughness values of samples machined at various discharge energies using $25 \mathrm{~g} / 1$ silver powder concentration.

\subsection{Silver content and in vitro antibacterial evaluation}

As can be seen in Fig. 7, powder concentration plays a vital role in the silver content of the coating layer, whereby a higher powder concentration results in an increase of the deposited silver. Consequently, 11 samples machined and coated without silver and with silver contents from $1.58 \%$ to $9.61 \%$ were performed by applying 11 powder concentrations, thus allowing for the antibacterial evaluation based on the coating layer's silver content. The silver content's results from EDS analysis are semi-quantitative and include a possible \pm 0.2 wt.\% error. Nevertheless, these results are sufficient for the purpose of this study.

Fig. 8 shows microscopy evaluation of $S$. aureus bacteria expressing green fluorescent protein, in which each viable bacterium is visible as a green dot on the dark background at different silver contents of the 


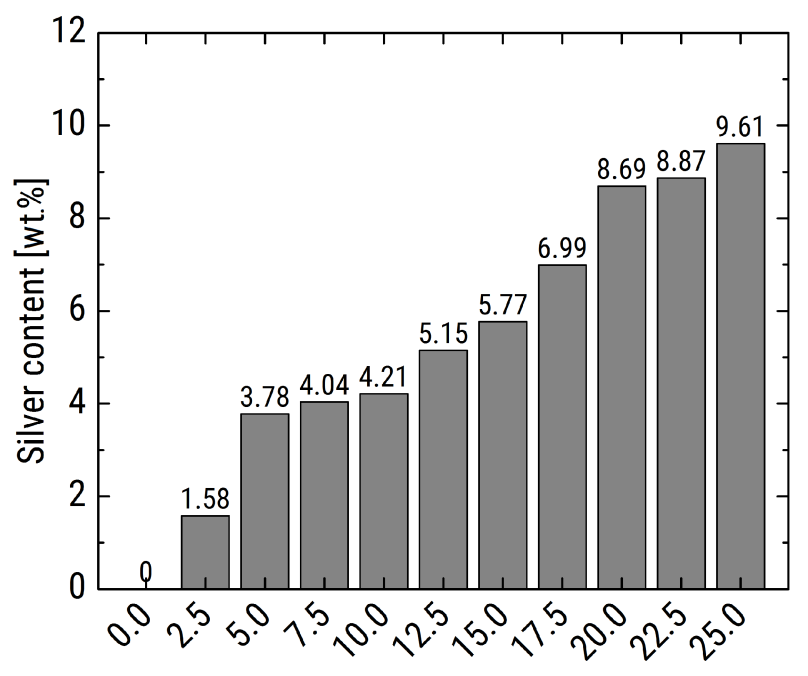

Powder concentration $[\mathrm{g} / \mathrm{l}]$

Figure 7: Silver content of the samples depending on powder concentration.

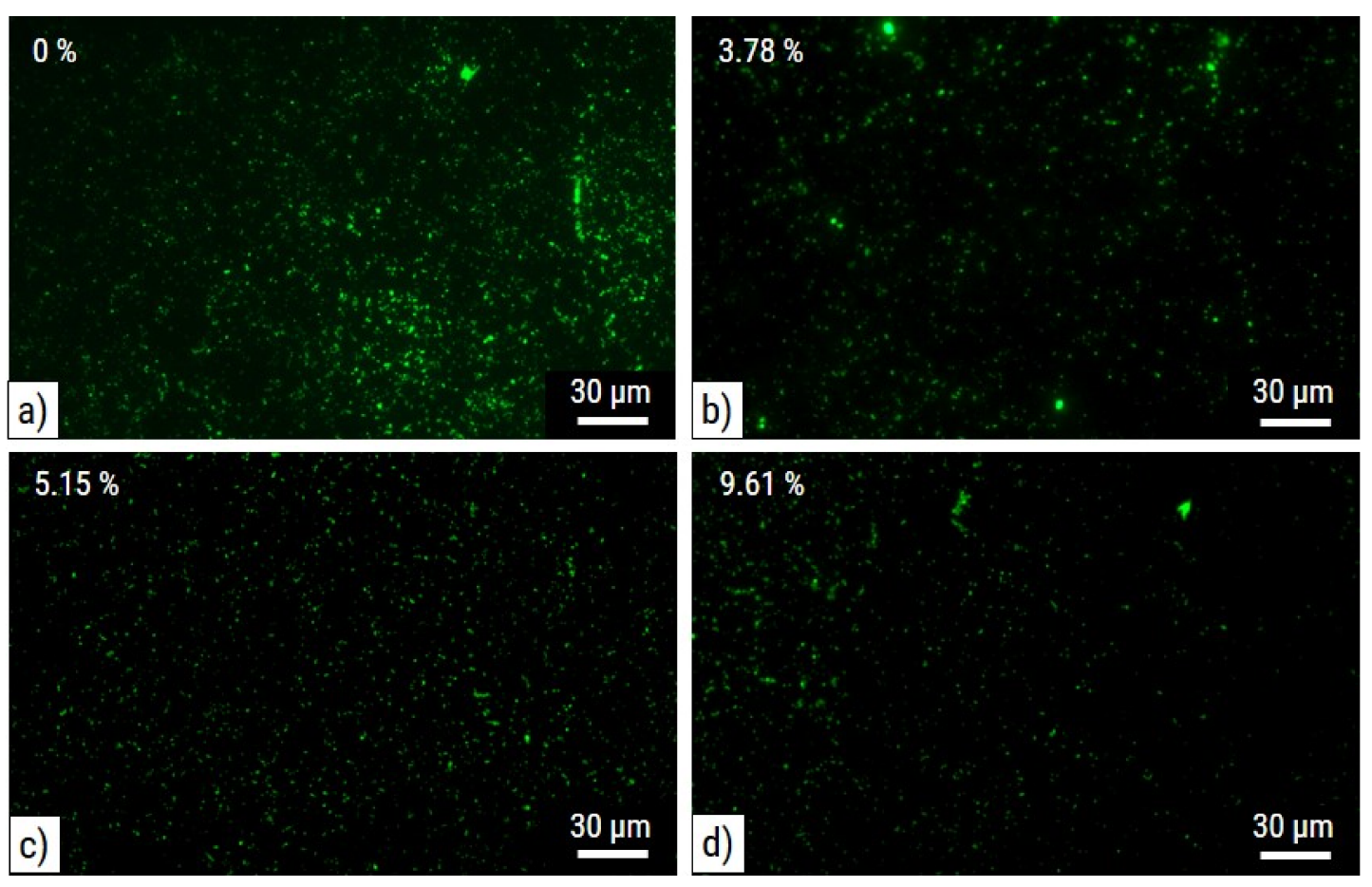

Figure 8: S. aureus bacterial mapping on the surfaces coated by silver contents of a) $0 \%$, b) $3.78 \%$, c) $5.15 \%$ and d) $9.61 \%$

coated Ti-6Al-4V test plate. The bacteria were cultivated for 24 hours before evaluating the amount of plate-adherent individual $S$. aureus bacteria and $S$. aureus clusters using epifluorescence microscopy. The quantification of adherent bacteria in Fig. 9 and bacterial clusters containing a larger number of $S$. aureus in Fig. 10 is shown in the graphs below. It was observed that the surfaces containing silver exhibit an 
number of $\mathrm{S}$. aureus

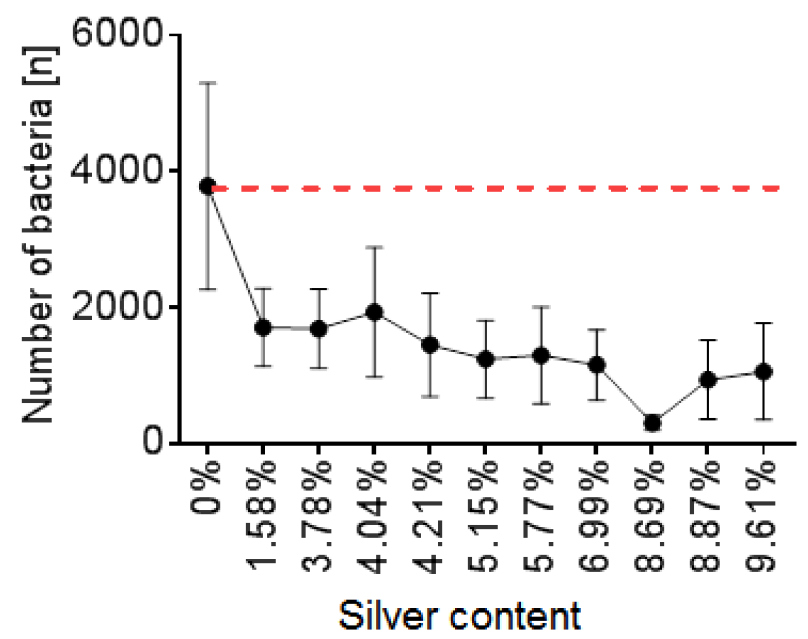

S. aureus cluster

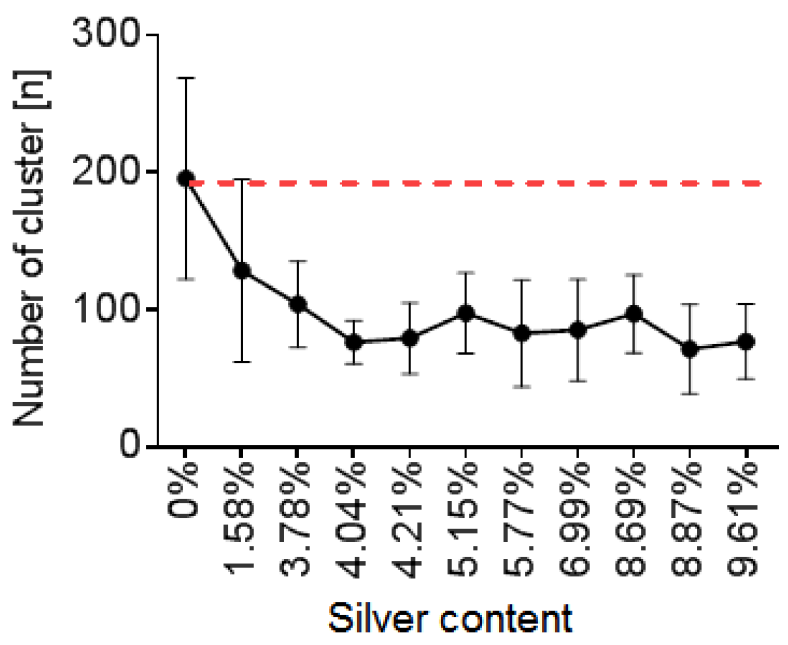

Figure 9: Influence of silver content on the number of bacteria. Figure 10: The number of clusters on the sample's surfaces.

antibacterial effect with a significant reduction of both individual bacteria as well as bacterial clusters. A significant reduction in bacterial numbers and clusters was observed already at $3.78 \%$ of silver with no significant further decrease in bacterial and cluster numbers at higher silver contents. Of note, some $S$. aureus bacteria, as well as clusters, remained even at very high silver concentrations $9.61 \%$.

It is known that bacteria can acquire a resistance towards silver mediated by the silver-resistance genes (silE, silS and silP) in bacteria [36], which can also occur in S. aureus strains [37]. A recent study, however, showed that the prevalence in silver resistance in S. aureus was only about $6 \%$ and restricted to the presence of the silE gene. Interestingly the silver resistant bacteria remained sensitive against silver in the tested wound dressing anyway [38]. Another study using a silver-hydroxyapatite coating on implants has also shown that about $3 \%$ silver embedded in a hydroxyapatite matrix reduced, but did not fully prevent, MethicillinResistant Staphylococcus Aureus (MRSA) biofilm formation [39], which is in line with the results from this study. Silver has been shown to enhance the effectiveness of antibiotics [40], therefore, the incomplete eradication of $S$. aureus in our experiments should not be a problem for the in vivo application, as normally antibiotics are given after endoprosthetic joint replacement.

\subsection{Analysis of silver distribution on and in the coating layer}

It can be seen from Fig. 11 that some silver was stuck on the machined surface. Since the samples were cleaned in an ultrasonic bath for 10 minutes with the machined surface facing downwards, it can therefore be concluded that this sticking phenomenon was not caused by settling of silver powder during the cleaning process. Based on the PMEDM mechanism, it is possible to explain that some of the observed silver powder was as a result of the spattering process, whereas the rest are from a fresh reflow of dielectric fluid which 

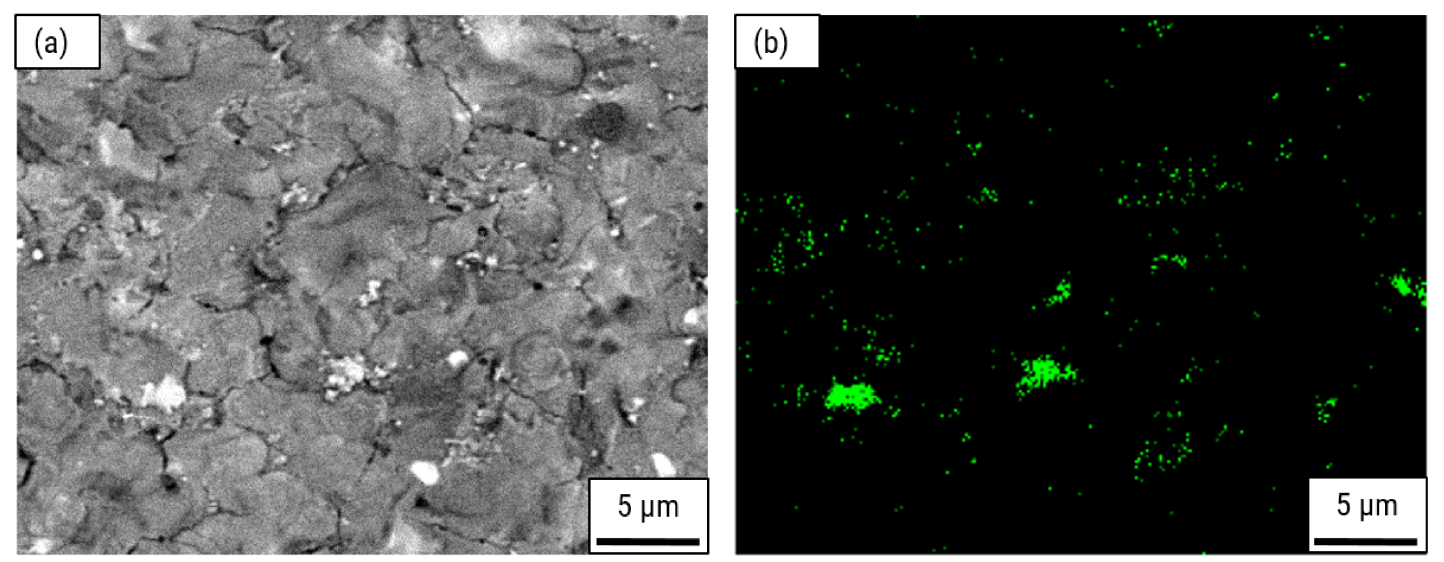

Figure 11: Distribution of silver on the coating layer for samples machined using dielectric fluid with $15 \mathrm{~g} / \mathrm{l}$ powder concentra-

tion: (a) SEM image and (b) silver mapping (identical area).

occurred when the coating layer was still molten after discharge. Silver sticking on the machined surface is one of the major challenges facing PMEDM for medical applications.

possible to coat a continuous layer on the Ti-6Al-4V surface. EDS analysis shows that materials from the workpiece, tool electrode as well as the dielectric fluid are contained in the coating layer. Furthermore, Figs. 11 and 12 show that silver is not only deposited on the machined surface, but also implanted in the recast layer. During machining, owing to a very high temperature in the plasma channel (approximately $10.000{ }^{\circ} \mathrm{K}$ ) as well as a thermal evaporation process, silver is molten and mixed with other molten material from tool electrode and workpiece, as well as mixed with carbon from the hydrocarbon-based dielectric fluid. After discharge, the coating layer is formed through a re-solidification process. Silver contained in the coating layer can be categorized into three morphologies: alloying of molten silver with the molten tool and workpiece materials; embedded silver particles on and into the coating layer; and spattered silver re-solidified on the coating surface. Therefore, the silver distribution of the coating layer is complex. However, silver content decreases within the coating layer towards the substrate surface.

In order to analyse the coating layer thickness, a Keyence VK9700 3D Laser scanning confocal-microscope was used to scan the surface after which a Keyence VK analyser software was used to analyse the coating layer's cross sectional thickness as shown in Fig. 13. Fifty areas with different coating thicknesses were analysed thus allowing for a calculation of an average thickness as well as standard deviation. From the results, it can be established that a $2.49^{ \pm 0.5} \mu \mathrm{m}$ thick coating layer could be coated by using a $17.5 \mu \mathrm{J}$ discharge energy. 

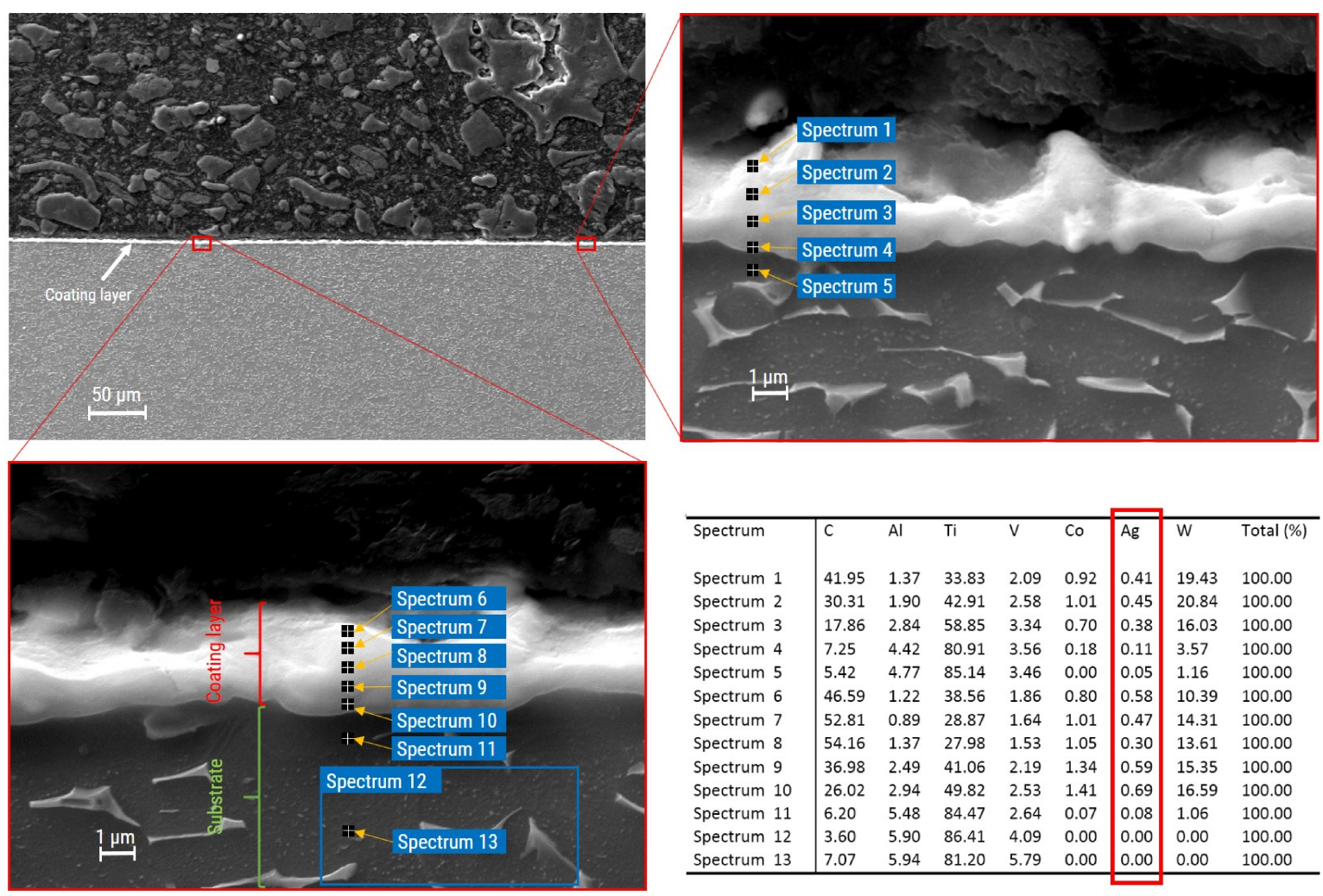

\begin{tabular}{l|lllll|l|ll}
\hline Spectrum & C & Al & Ti & V & Co & Ag & W & Total (\%) \\
& & & & & & & & \\
Spectrum 1 & 41.95 & 1.37 & 33.83 & 2.09 & 0.92 & 0.41 & 19.43 & 100.00 \\
Spectrum 2 & 30.31 & 1.90 & 42.91 & 2.58 & 1.01 & 0.45 & 20.84 & 100.00 \\
Spectrum 3 & 17.86 & 2.84 & 58.85 & 3.34 & 0.70 & 0.38 & 16.03 & 100.00 \\
Spectrum 4 & 7.25 & 4.42 & 80.91 & 3.56 & 0.18 & 0.11 & 3.57 & 100.00 \\
Spectrum 5 & 5.42 & 4.77 & 85.14 & 3.46 & 0.00 & 0.05 & 1.16 & 100.00 \\
Spectrum 6 & 46.59 & 1.22 & 38.56 & 1.86 & 0.80 & 0.58 & 10.39 & 100.00 \\
Spectrum 7 & 52.81 & 0.89 & 28.87 & 1.64 & 1.01 & 0.47 & 14.31 & 100.00 \\
Spectrum 8 & 54.16 & 1.37 & 27.98 & 1.53 & 1.05 & 0.30 & 13.61 & 100.00 \\
Spectrum 9 & 36.98 & 2.49 & 41.06 & 2.19 & 1.34 & 0.59 & 15.35 & 100.00 \\
Spectrum 10 & 26.02 & 2.94 & 49.82 & 2.53 & 1.41 & 0.69 & 16.59 & 100.00 \\
Spectrum 11 & 6.20 & 5.48 & 84.47 & 2.64 & 0.07 & 0.08 & 1.06 & 100.00 \\
Spectrum 12 & 3.60 & 5.90 & 86.41 & 4.09 & 0.00 & 0.00 & 0.00 & 100.00 \\
Spectrum 13 & 7.07 & 5.94 & 81.20 & 5.79 & 0.00 & 0.00 & 0.00 & 100.00 \\
\hline
\end{tabular}

Figure 12: SEM and EDS analysis of the coating layer showing how silver content varies with coat depth.

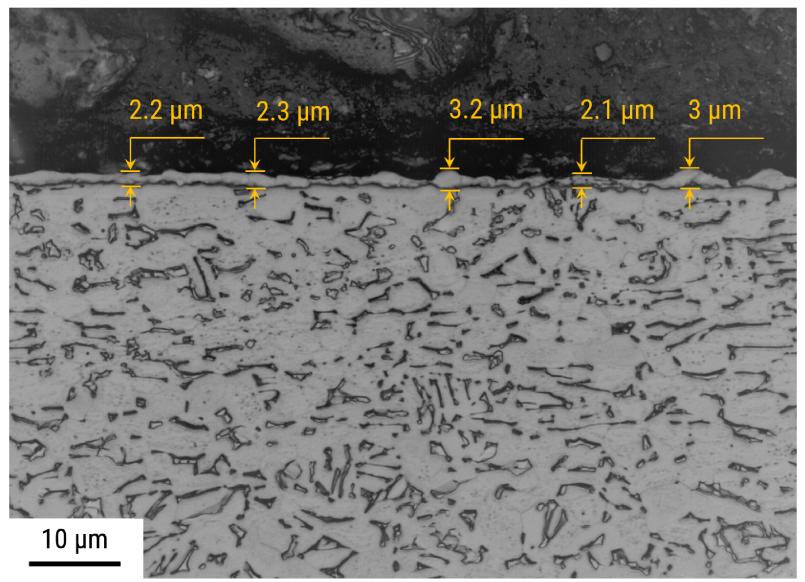

Figure 13: Coating layer thicknesses for a sample machined and coated using a $17.5 \mu \mathrm{J}$ discharge energy.

\subsection{Analysis of the coating layer's microhardness}

A nanoindenter was used to measure the microhardness of both Ti-6Al-4V substrate as well as the coating surfaces varying silver contents. The tested nanoindentation positions on the sample are shown in Fig. 14. The indentation point was also scanned by a Keyence VK9700 3D Laser scanning confocal- 
microscope. Afterwards, MountainsMap 7.4 scanning topography software was used to analyse and check the indentation depth. From Fig. 14, a $\approx 0.7 \mu \mathrm{m}$ depth of the indentation could be realised.
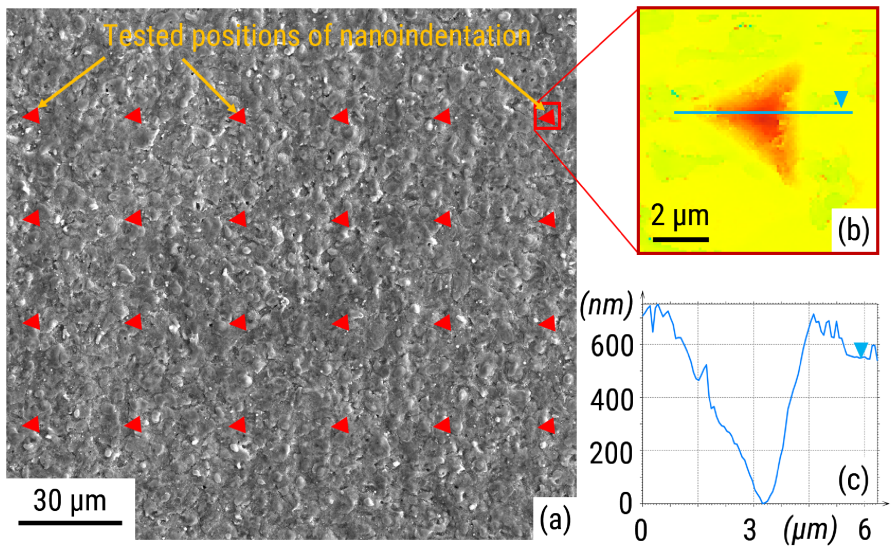

Figure 14: (a) Sample surface showing nanoindentation positions (in red color) used to test for microhardness, (b) the nanoindentation's graph and (c) depth profile.

As shown in Tab. 2, the microhardness of Ti-6Al-4V is 379.18 (HV). After EDM without powder, a coating layer with a 528.39 (HV) microhardness was coated on the substrate surface. By using nano-silver particles mixed into the dielectric fluid in PMEDM, a reduction of the coating layer's microhardness, due to the deposition of silver, could be established, whereby an increase of silver content reduces the surface hardness.

Table 2: Microhardness values for both Ti-6Al-4V substrate as well as the coating layers containing various silver contents

\begin{tabular}{lllll}
\hline & Ti-6Al-4V & \multicolumn{3}{c}{ The coating layers containing different silver contents } \\
\cline { 2 - 5 } & substrate & 0 (wt.\%) $\mathrm{Ag}$ & $3.78($ wt.\%) $\mathrm{Ag}$ & 9.61 (wt.\%) Ag \\
\hline Microhardness (HV) & 379.18 & 528.39 & 527.19 & 521.62 \\
\hline
\end{tabular}

\subsection{Analysis of the process efficiency}

It is clear that EDM without powder has been widely used for machining medical devices. However, long machining time is still a challenge for this process. The addition of silver nano-particles into the dielectric fluid, in this study, is used not only for machining Ti- $6 \mathrm{Al}-4 \mathrm{~V}$, but also for reducing the machining time. The results showed that MRR, compared to the EDM without powder, is significantly enhanced by suspending powder particles in a hydrocarbon-based dielectric fluid. For example, as can be seen in Fig. 15, the material removal rate is improved from $\approx 0.007$ to $\approx 0.02\left(\mathrm{~mm}^{3} / \mathrm{min}\right)$ by using $10 \mathrm{~g} / \mathrm{l}$ silver powder concentration.

In explanation, this increase can be attributed to fact that the addition of silver powder reduces dielectric resistivity, resulting in an enlargement of the machining gap, which enhances flushing conditions. Simulta- 


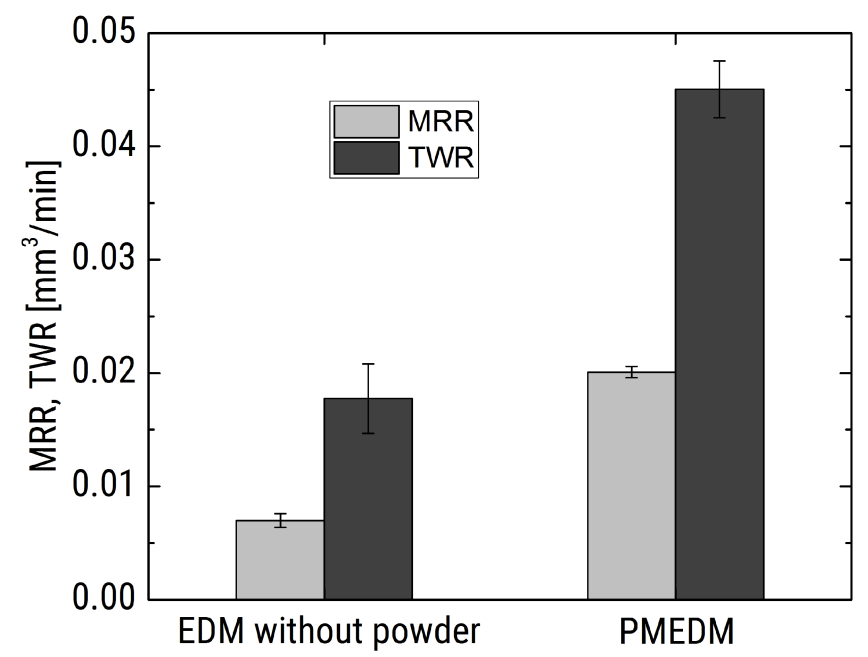

Figure 15: Comparison of material removal rate (MRR) and tool wear rate (TWR) between EDM without powder and PMEDM using $10 \mathrm{~g} / \mathrm{l}$ silver powder concentration and $9.98 \mu \mathrm{J}$ discharge energy.

neously, the presence of silver particles in the discharge gap facilitates better spark ignition. Therefore, the number of pulses, which is a primary reason for the improvement in MRR, is increased.

In order to prove this explanation, during the experiments, pulse signals were recorded for $20 \mathrm{~ms}$ using a Tektronix DPO4101 digital oscilloscope with a TCP312 current and P6139A voltage probe. Afterwards, MATLAB R2017 software was utilised to analyse these signals. The results show that the pulse number per time of PMEDM is higher than that of EDM without powder (Fig. 16). The number of pulses for $20 \mathrm{ms,}$ as compared to EDM without powder, increases from 1758 to 5090 by using $10 \mathrm{~g} / \mathrm{l}$ powder concentration.

This pulse increase affects both MRR and TWR whereby, owing to the relative erosive wear between electrodes, as compared to EDM without powder, TWR using PMEDM is also significantly increased (Fig. 15). However, wear ratio, which is calculated by the quotient of TWR per MRR, is reduced from $\approx 2.54$ to $\approx 2.32$.

As part of the PMEDM efficiency on machining, surface roughness and structure, on the other hand, due to the influence on the bacterial adhesion and growth, are important factors that needed to be analysed.

As can be seen in Tab. 3, the surface roughness of the samples machined by EDM without powder and PMEDM using varying powder concentrations and $9.98 \mu \mathrm{J}$ pulse energy are represented. It can be realized that all samples have surface roughness values not larger than $0.2 \mu \mathrm{m}$ in $\mathrm{R}_{a}$ which fits with the aforementioned designed surface roughness upper threshold. Other surface roughness parameters such as $\mathrm{R}_{z}$ and $\mathrm{R}_{v k}$ are also vital as they have a relationship with the adhesion of bacteria [41].

Furthermore, surface roughness values of all samples are relatively similar. This similarity of the surface roughness values is significant for further antimicrobial evaluation since it allows to attribute any differences on the observed antibacterial properties to the silver content. If the surface roughness values were significantly varied, then their contribution to bacterial adhesion and accommodation would have to be separately 


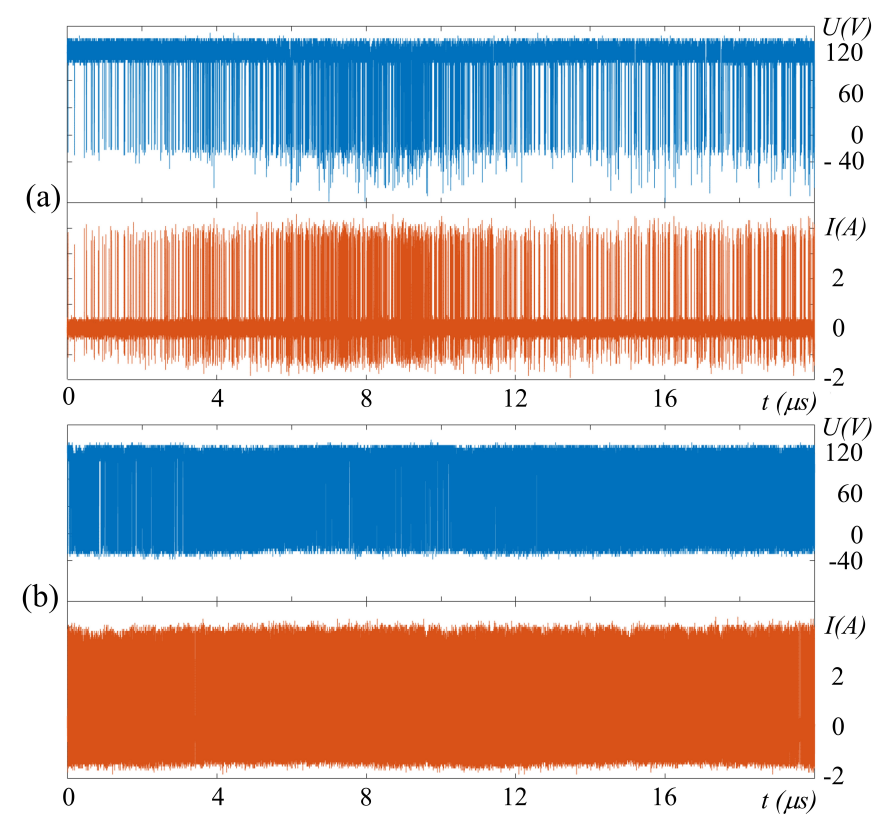

Figure 16: Current and voltage waveforms: (a) EDM without powder and (b) PMEDM with $10 \mathrm{~g} / \mathrm{l}$ powder concentration.

Table 3: Surface roughness of the samples machined by EDM without powder and PMEDM with different powder concentrations, using $9.98 \mu \mathrm{J}$ discharge energy.

\begin{tabular}{llllllllllll}
\hline $\begin{array}{l}\text { Powder concen- } \\
\text { tration }(\mathrm{g} / \mathrm{l})\end{array}$ & 0 & 2.5 & 5 & 7.5 & 10 & 12.5 & 15 & 17.5 & 20 & 22.5 & 25 \\
\hline $\mathrm{R}_{a}(\mu \mathrm{m})$ & 0.2 & 0.169 & 0.173 & 0.166 & 0.155 & 0.167 & 0.181 & 0.162 & 0.169 & 0.159 & 0.171 \\
$\mathrm{R}_{z}(\mu \mathrm{m})$ & 1.45 & 1.25 & 1.14 & 1.26 & 1.21 & 1.33 & 1.23 & 1.27 & 1.14 & 1.23 & 1.15 \\
$\mathrm{R}_{v k}(\mu \mathrm{m})$ & 0.283 & 0.227 & 0.218 & 0.22 & 0.214 & 0.215 & 0.223 & 0.206 & 0.231 & 0.203 & 0.221 \\
\hline
\end{tabular}

factored into the analysis.

Although having relatively similar surface roughness values by varying powder concentration suspended in the dielectric fluid, surface structures of the samples should be analysed. EDMed surface structures are very complex because they are formed by a combination of overlapping craters and layers of spattered material from the discharges. Consequently, in order to analyse surface structure of the samples, MountainsMap 7.4 scanning topography software was used. Fig. 17 shows 3D images of the machined surfaces with various silver concentrations mixed into the dielectric fluid (Fig. 17b, c and d) and without powder (Fig. 17a). It can be seen that the surface machined using EDM without powder has slightly bigger and higher peaks than PMEDMed surfaces. However, there is no obvious difference in the surface structure of the samples.

Based on the results regarding material removal rate, tool wear, the surface roughness and structure, as well as the deposited silver content, it can be established that the machining time of PMEDM is significantly 

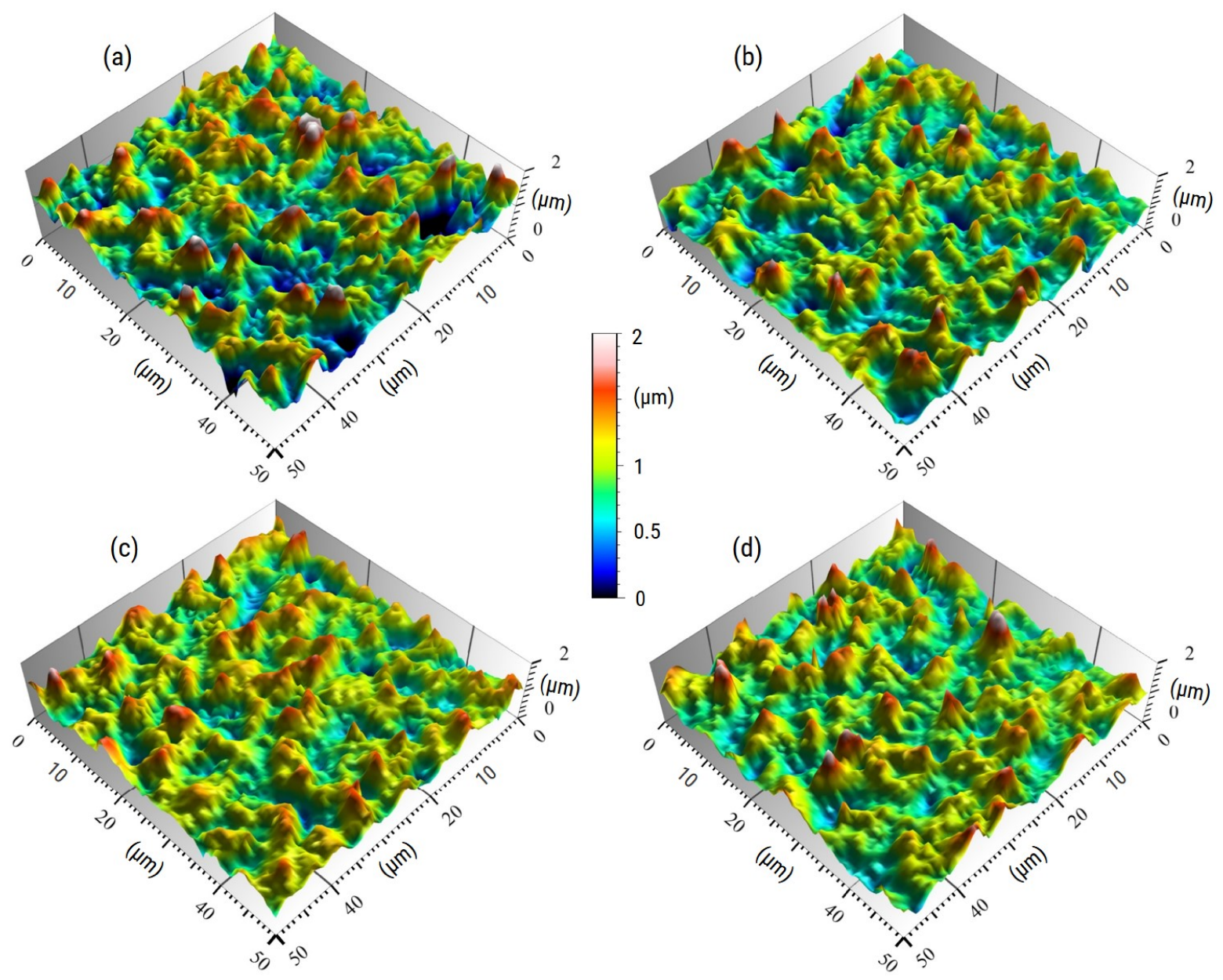

Figure 17: 3D images: (a) EDMed surface machined without powder; and PMEDMed surfaces machined using (b) $5 \mathrm{~g} / \mathrm{l}$, (c) $15 \mathrm{~g} / 1$ and (d) $25 \mathrm{~g} / 1$ silver powder concentrations.

reduced as compared to EDM without powder, whereas the surface quality is similar. Therefore, PMEDM has demonstrated its ability in not only improving the machining efficiency, but also in coating layers with controllable silver contents on the workpiece surface, while at the same time resulting in negligible changes in surface roughness and structure. All of these abilities of PMEDM have an effect on antibacterial properties. Therefore, it is possible to concurrently machine and coat surfaces fulfilling specific requirements regarding both silver content and surface quality using the PMEDM method.

\section{Conclusions}

In this study, the capability of PMEDM using silver nano-particles in machining Ti-6Al-4V medical material and coating an antibacterial layer on the machined surface has been investigated. From the results, the following conclusions can be drawn: 
- It is possible to realise a continuous coating layer incorporating constituent elements from tool electrode, workpiece, dielectric fluid as well as powder particles which were deposited during the machining and coating process.

- Silver content in the coating layer tends to decrease with increasing depth of coat.

- Both qualitative and quantitative antibacterial results have demonstrated an excellent antibacterial property of the surfaces which are machined and coated by the PMEDM method.

- Silver content in the coating layer plays a vital role in reducing the amount of not only $S$. aureus, but also bacterial cluster on the coating surfaces.

- Machining efficiency is significantly enhanced by suspending silver particles into dielectric fluid. It is possible to increase material removal rate of EDM process up to $\approx 286 \%$ whereas wear ratio is reduced by $\approx 8.7 \%$.

- PMEDM has demonstrated a considerable potential to concurrently machine geometry's part and coat antibacterial layers on medical devices.

\section{Acknowledgements}

The authors are thankful to TU Chemnitz, OVGU Magdeburg, Fraunhofer IWU, German Academic Exchange Service and Vietnam Ministry of Education and Training for facilitating this research.

\section{References}

[1] Lucintel, Medical Device Market Report: Trends, Forecast and Competitive Analysis, Tech. rep. (2018). URL http://www.lucintel.com/medical-device-market-2018.aspx

[2] ResearchAndMarkets, Global Medical Devices Market- Technologies, Market share and Industry Forecast to 2024 (2018). URL https://www.researchandmarkets.com/research/ncj3nf/global\{_\}medical?w=5

[3] J. R. Lentino, Prosthetic Joint Infections: Bane of Orthopedists, Challenge for Infectious Disease Specialists, Clinical Infectious Diseases 36 (9) (2003) 1157-1161. doi:10.1086/374554.

[4] M. Cloutier, D. Mantovani, F. Rosei, Antibacterial Coatings: Challenges, Perspectives, and Opportunities, Trends in Biotechnology 33 (11) (2015) 637-652. doi:10.1016/j.tibtech.2015.09.002.

[5] N. Ohtsu, K. Yokoi, A. Saito, Fabrication of a visible-light-responsive photocatalytic antibacterial coating on titanium through anodic oxidation in a nitrate/ethylene glycol electrolyte, Surface and Coatings Technology 262 (2015) 97-102. doi:10.1016/j.surfcoat.2014.12.021.

[6] B. S. Necula, J. P. Van Leeuwen, L. E. Fratila-Apachitei, S. A. Zaat, I. Apachitei, J. Duszczyk, In vitro cytotoxicity evaluation of porous TiO2-Ag antibacterial coatings for human fetal osteoblasts, Acta Biomaterialia 8 (11) (2012) 41914197. doi:10.1016/j.actbio.2012.07.005.

[7] C. Gasquères, G. Schneider, R. Nusko, G. Maier, E. Dingeldein, A. Eliezer, Innovative antibacterial coating by anodic spark deposition, Surface and Coatings Technology 206 (15) (2012) 3410-3414. doi:10.1016/j.surfcoat.2012.02.015. 
[8] B. Li, X. Liu, F. Meng, J. Chang, C. Ding, Preparation and antibacterial properties of plasma sprayed nano-titania/silver coatings, Materials Chemistry and Physics 118 (1) (2009) 99-104. doi:10.1002/jbm.b.31434.

[9] A. Ewald, S. K. Glückermann, R. Thull, U. Gbureck, Antimicrobial titanium/silver PVD coatings on titanium, BioMedical Engineering Online 5 (1) (2006) 22. doi:10.1186/1475-925X-5-22.

[10] S. Varghese, S. Elfakhri, D. W. Sheel, P. Sheel, F. J. Bolton, H. A. Foster, Novel antibacterial silver-silica surface coatings prepared by chemical vapour deposition for infection control, Journal of Applied Microbiology 115 (5) (2013) $1107-1116$. doi: $10.1111 /$ jam. 12308 .

[11] T. Schmitz, Functional coatings by physical vapor deposition (PVD) for biomedical applications, Doctoral dissertation, Julius Maximilian University Wuerzburg (2016).

URL https://opus.bibliothek.uni-wuerzburg.de/opus4-wuerzburg/frontdoor/deliver/index/docId/14482/file/ Schmitz\{_\}Tobias\{_\}vapor\{_\}deposition.pdf

[12] J. M. Lackner, W. Waldhauser, Inorganic PVD and CVD coatings in medicine A review of protein and cell adhesion on coated surfaces, Journal of Adhesion Science and Technology 24 (5) (2010) 925-961. doi:10.1163/ $016942409 \times 12598231568023$.

[13] T. Shimazaki, H. Miyamoto, Y. Ando, I. Noda, Y. Yonekura, S. Kawano, M. Miyazaki, M. Mawatari, T. Hotokebuchi, In vivo antibacterial and silver-releasing properties of novel thermal sprayed silver-containing hydroxyapatite coating (2010). doi:10.1002/jbm.b.31526.

[14] T. Akiyama, H. Miyamoto, Y. Yonekura, M. Tsukamoto, Y. Ando, I. Noda, M. Sonohata, M. Mawatari, Silver oxidecontaining hydroxyapatite coating has in vivo antibacterial activity in the rat tibia (2013). doi:10.1002/jor.22357.

[15] S. Mei, H. Wang, W. Wang, L. Tong, H. Pan, C. Ruan, Q. Ma, M. Liu, H. Yang, L. Zhang, Y. Cheng, Y. Zhang, L. Zhao, P. K. Chu, Antibacterial effects and biocompatibility of titanium surfaces with graded silver incorporation in titania nanotubes, Biomaterials 35 (14) (2014) 4255-4265. doi:10.1016/j.biomaterials.2014.02.005.

[16] H. Cao, Y. Qiao, X. Liu, T. Lu, T. Cui, F. Meng, P. K. Chu, Electron storage mediated dark antibacterial action of bound silver nanoparticles: Smaller is not always better, Acta Biomaterialia 9 (2) (2013) 5100-5110. doi:10.1016/j.actbio. 2012.10 .017 .

[17] Y. Z. Wan, S. Raman, F. He, Y. Huang, Surface modification of medical metals by ion implantation of silver and copper, Vacuum 81 (9) (2007) 1114-1118. doi:10.1016/j.vacuum.2006.12.011.

[18] V. D. Bui, J. W. Mwangi, A. Schubert, Powder mixed electrical discharge machining for antibacterial coating on titanium implant surfaces, Journal of Manufacturing Processes 44 (2019) 261-270. doi:10.1016/j.jmapro.2019.05.032.

[19] C. Prakash, H. K. Kansal, B. S. Pabla, S. Puri, Potential of powder mixed electric discharge machining to enhance the wear and tribological performance of $\beta$ - Ti implant for orthopedic applications, Journal of Nanoengineering and Nanomanufacturing 5 (4) (2015) 261-269. doi:10.1166/jnan.2015.1245.

[20] C. Prakash, H. K. Kansal, B. S. Pabla, S. Puri, Powder mixed electric discharge machining: An innovative surface modification technique to enhance fatigue performance and bioactivity of $\beta$-Ti implant for orthopedics application, Journal of Computing and Information Science in Engineering 16 (4) (2016) 041006.

[21] P. Janmanee, A. Muttamara, Surface modification of tungsten carbide by electrical discharge coating (EDC) using a titanium powder suspension, Applied Surface Science 258 (19) (2012) 7255-7265.

[22] A. Molinetti, F. L. Amorim, P. C. Soares, T. Czelusniak, Surface modification of AISI H13 tool steel with silicon or manganese powders mixed to the dielectric in electrical discharge machining process, The International Journal of Advanced Manufacturing Technology 83 (5-8) (2016) 1057-1068. doi:10.1007/s00170-015-7613-1.

[23] A. Bhattacharya, A. Batish, G. Singh, Surface modification of high carbon high chromium, EN31 and hot die steel using powder mixed EDM process, Materials science forum 701 (2012) 43-59. doi:10.4028/www.scientific.net/MSF.701.43.

[24] Y. F. Chen, Y. C. Lin, Surface modifications of Al-Zn-Mg alloy using combined EDM with ultrasonic machining and 
addition of TiC particles into the dielectric, Journal of Materials Processing Technology 209 (9) (2009) 4343-4350. doi: 10.1016/j.jmatprotec.2008.11.013.

[25] A. Bhattacharya, A. Batish, N. Kumar, Surface characterization and material migration during surface modification of die steels with silicon, graphite and tungsten powder in EDM process, Journal of Mechanical Science and Technology 27 (1) (2013) 133-140. doi:10.1007/s12206-012-0883-8.

[26] A. A. Khan, M. B. Ndaliman, Z. M. Zain, M. F. Jamaludin, U. Patthi, Surface Modification Using Electric Discharge Machining (EDM) with Powder Addition, Applied Mechanics and Materials 110 (2012) 725-733. doi:10.4028/www. scientific.net/AMM.110-116.725.

[27] T. Yih-fong, C. Fu-chen, Investigation into some surface characteristics of electrical discharge machined SKD-11 using powder-suspension dielectric oil, Journal of Materials Processing Technology 170 (2005) 385-391. doi:10.1016/j. jmatprotec.2005.06.006.

[28] F. L. Amorim, V. A. Dalcin, P. Soares, L. A. Mendes, Surface modification of tool steel by electrical discharge machining with molybdenum powder mixed in dielectric fluid, International Journal of Advanced Manufacturing Technology 91 (1-4) (2017) 341-350. doi:10.1007/s00170-016-9678-x.

[29] H. K. Kansal, S. Singh, P. Kumar, Numerical simulation of powder mixed electric discharge machining (PMEDM) using finite element method, Mathematical and Computer Modelling 47 (11-12) (2008) 1217-1237. doi:10.1016/j.mcm.2007. 05.016.

[30] W. S. Zhao, Q. G. Meng, Z. L. Wang, The application of research on powder mixed EDM in rough machining, Journal of Materials Processing Technology 129 (1-3) (2002) 30-33. doi:10.1016/S0924-0136(02)00570-8.

[31] C. M. Bollenl, P. Lambrechts, M. Quirynen, Comparison of surface roughness of oral hard materials to the threshold surface roughness for bacterial plaque retention: A review of the literature, Dental materials 13 (4) (1997) $258-269$. doi : 10.1007/s00167-015-3756-8.

[32] W. Teughels, N. Van Assche, I. Sliepen, M. Quirynen, Effect of material characteristics and/or surface topography on biofilm development, Clinical Oral Implants Research 17 (S2) (2006) 68-81.

[33] V. D. Bui, J. W. Mwangi, T. Berger, A. Schubert, Investigating the potential of electrical discharge machining for antibacterial coating of titanium implants, euspen's 18th International Conference \& Exhibition (2018) 393-394.

[34] V. D. Bui, J. W. Mwangi, A. Schubert, Effect of tool electrode size and pulse energy on surface integrity of titanium implant in electrical discharge milling, in: Medical Device Manufacturing Conference, 2018, pp. 59-61.

[35] S. N. a. Qazi, E. Counil, J. Morrissey, C. E. D. Rees, A. Cockayne, K. Winzer, W. C. Chan, P. Williams, P. J. Hill, agr expression precedes escape of internalized Staphylococcus aureus from the host endosome, Infection and Immunity 69 (11) (2001) 7074-7082. doi:10.1128/IAI.69.11.7074

[36] S. L. Percival, P. G. Bowler, D. Russell, Bacterial resistance to silver in wound care, Journal of Hospital Infection 60 (1) (2005) 1-7. doi:10.1016/j.jhin.2004.11.014.

[37] K. E. Baptiste, K. Williams, N. J. Willams, A. Wattret, P. D. Clegg, S. Dawson, J. E. Corkill, T. O’Neill, A. C. Hart, Methicillin-resistant staphylococci in companion animals, Emerging Infectious Diseases 11 (12) (2005) $1942-1944$. doi:10.3201/eid1112.050241.

[38] J. V. Loh, S. L. Percival, E. J. Woods, N. J. Williams, C. A. Cochrane, Silver resistance in MRSA isolated from wound and nasal sources in humans and animals, International Wound Journal 6 (1) (2009) 32-38.

[39] M. Ueno, H. Miyamoto, M. Tsukamoto, S. Eto, I. Noda, T. Shobuike, T. Kobatake, M. Sonohata, M. Mawatari, Silvercontaining hydroxyapatite coating reduces biofilm formation by methicillin-resistant Staphylococcus aureus in vitro and in vivo, BioMed Research International 2016 (2016) 7. doi:10.1155/2016/8070597.

[40] J. R. Morones-Ramirez, J. A. Winkler, C. S. Spina, J. J. Collins, Silver enhances antibiotic activity against gram-negative bacteria, Science translational medicine 5 (190) (2013) 29. doi:10.1126/scitranslmed.3006276.190ra81. 
[41] C. Faille, C. Jullien, F. Fontaine, M.-N. Bellon-Fontaine, C. Slomianny, T. Benezech, Adhesion of Bacillus spores and Escherichia coli cells to inert surfaces: role of surface hydrophobicity, Canadian Journal of Microbiology 48 (8) (2002) 728-738. doi:10.1139/w02-063. 